\title{
Penghimpunan Dan Distribusi Dana Zakat Baznas Daerah
}

\author{
Etti Eriani' ${ }^{1}$ Muhammd Arsyad ${ }^{2}$, Rodame Monitorir Napitupulu3 ${ }^{3}$ \\ ettieriani.e2@gmail.com ${ }^{1}$, rodamenapitupulu@iain-padangsidimpuan.ac.id33 \\ Institut Agama Islam Negeri Padangsidimpuan ${ }^{1,2,3}$ \\ Email : napitupulurm@gmail.com
}

\begin{abstract}
Abstrak
Penelitian ini dilatarbelakangi adanya realita bahwa setiap tahunnya penghimpunan dari dana zakat cenderung menurun sehingga berdampak pada distribusi yang dilakukan oleh BAZNAS Daerah Kabupaten Tapanuli Selatan. Tujuan penelitian ini ialah untuk mengetahui metode penghimpunan dan distribusi dana zakat yang dilakukan BAZNAS Daerah Kabupaten Tapanuli Selatan. Jenis penelitian ini ialah penelitian kualitatif dengan menggunakan pendekatan deskriptif. Sumber data yang digunakan adalah data primer. Teknik pengumpulan data yang digunakan oleh peneliti ialah dengan menggunakan wawancara, observasi dan dokumentasi dengan struktural yang ada di BAZNAS Daerah Kabupaten Tapanuli Selatan. Hasil penelitian ini menunjukkan bahwa metode penghimpunan dana zakat pada BAZNAS Daerah Kabupaten Tapanuli Selatan menggunakan metode penghimpunan berupa kerjasama dengan ASN (Aparatur Sipil Negara), dan beberapa donatur yang memberikan zakat kepada Amil hanya bagi mereka yang sadar akan kewajiban menunaikan zakat sedangkan metode distribusi dana zakat yang dilakukan oleh BAZNAS Daerah Kabupaten Tapanuli Selatan dengan metode langsung yang bersifat konsumtif dan produktif dengan empat bidang yaitu Bidang Ekonomi, Pendidikan, Kesehatan dan Sosial.
\end{abstract}

\section{Kata Kunci: Penghimpunan Zakat, Distribusi Zakat, Kinerja BAZNAS Daerah}

\begin{abstract}
The aim of this research is to know zakat fund collection method and zakat fund distribution that carried out by BAZNAS in South Tapanuli Regency. This research approach is qualitative descriptive. The data source used is primary data. The data collection technique used by researchers is to use interviews, observation and structural documentation in the BAZNAS of South Tapanuli Regency.The results of this study indicate that the method of collecting zakat funds in the BAZNAS of South Tapanuli Regency uses the collection method in the form of cooperation with ASN (State Civil Apparatus), and some donors who give zakat to Amil are only for those who are aware of the obligation to pay zakat while the method of distributing zakat funds conducted by the BAZNAS of South Tapanuli Regency with direct methods that are consumptive and productive in four fields, namely: Economic, Education, Health and Social.
\end{abstract}

Keywords: Zakat Fund Collection, Zakat Distribution, Regional BAZNAS Performance. 


\section{PENDAHULUAN}

Kewajiban zakat dengan tegas diperintahkan Allah dalam berbagai firman-Nya. Zakat ditunaikan oleh mereka yang mengharapkan balasan Allah di akhirat, dan kadang-kadang ditinggalkan oleh mereka yang kurang yakin terhadap balasan akhirat (Qardawi, 1985). Zakat bukan hanya sekedar rukun Islam, tetapi juga sebagai penentu apakah seseorang itu menjadi saudara seagama atau tidak. Dilihat dari sisi hikmah, zakat memiliki dua dimensi, dimensi vertikal dan dimensi horizontal. Artinya, zakat menjadi perwujudan ibadah seseorang kepada Allah dan juga sebagai perwujudan dari rasa kepedulian sosial (kesalehan sosial). Namun dalam malaksanakan kewajiban tersebut, orang yang membayar zakat (muzakki) tidak bisa terlepas dari urusan bersama (horizontal) karena zakat berkaitan dengan harta benda dan kepada siapa harta itu diberikan, sehingga sangat berkaitan dengan para penerima (mustahik).

Badan Amil Zakat Nasional (BAZNAS) merupakan badan resmi dan satu-satunya yang dibentuk oleh pemerintah berdasarkan Keputusan Presiden RI No. 8 Tahun 2001 yang memiliki tugas dan fungsi menghimpun dan menyalurkan zakat, infaq, dan sedekah (ZIS) pada tingkat nasional. Lahirnya Undang-Undang Nomor 23 Tahun 2011 tentang Pengelolaan Zakat semakin mengukuhkan peran BAZNAS sebagai lembaga yang berwenang melakukan pengelolaan zakat secara nasional. Dalam UU tersebut, BAZNAS dinyatakan sebagai lembaga pemerintah nonstruktural yang bersifat mandiri dan bertanggung jawab kepada Presiden melalui Menteri Agama. Dengan demikian, BAZNAS bersama Pemerintah bertanggung jawab untuk mengawal pengelolaan zakat yang berasaskan: syariat Islam, amanah, kemanfaatan, keadilan, kepastian hukum, terintegrasi dan akuntabilitas.

Pendistribusian zakat konsumtif juga memiliki beberapa kategori pendanaan seperti bantuan untuk para jompo (lansia) dan asnaf yang termasuk dalam kategori fakir dan miskin. Kedua pendistribusian zakat yang bersifat dana bergulir kategori asnaf penerima zakat ini yang pertama untuk konsumtif dan penambahan modal. Pendistribusian zakat ini diperoleh dari Aparatur Sipil Negara (ASN) Kabupaten Tapanuli Selatan. Selengkapnya dapat dilihat pada Tabel 1.

Pada daerah lain di Indonesia, penghimpunan zakat mal juga diatur dalam Peraturan Bupati (Mulyadi, 2018). Hal ini menunjukkan bahwa diperlukan dukungan dan keseriusan dari pemerintah daerah dalam menghimpun dana zakat. Pendistribusian dana zakat pada BAZNAS Daerah Kabupaten Tapanuli Selatan di bagi pada 4 sektor yaitu ekonomi, pendidikan, kesehatan dan sosial yang presentasenya dapat dilihat pada Tabel sebagai berikut. 
Tabel 1

Distribusi Dana Zakat pada BAZNAS

Daerah Kabupaten Tapanuli Selatan

Tahun 2018

\begin{tabular}{|l|l|c|c|}
\hline NO & \multicolumn{1}{|c|}{ Sektor } & Jumlah (Rp) & \% \\
\hline $\mathbf{1}$ & Ekonomi & 330.000 .000 & $92,3 \%$ \\
\hline $\mathbf{2}$ & Pendidikan & 13.000 .000 & $3,64 \%$ \\
\hline 3 & Kesehatan & 8.000 .000 & $2,24 \%$ \\
\hline 4 & Sosial & 6.500 .000 & $1,82 \%$ \\
\hline \multicolumn{2}{|c|}{ Total } & 357.500 .000 & $100 \%$ \\
\hline
\end{tabular}

Sumber : BAZNAS Daerah KabupatenTapanuli Selatan (2019)

Dari Tabel 1 di atas dana distribusi terbagi pada 4 sektor. Jumlah distribusi dana tertinggi adalah pada sektor ekonomi 92,3\%\% dan pendidikan 3,64\% kemudian diikuti sektor kesehatan 2,24\% yang paling rendah pada sektor sosial pada tahun 2018 1,82\%. Sedangkan untuk perkembangan distribusi zakat Baznas dapat dilaihat pada Tabel dibwah ini

Tabel 2

Distribusi Dana Zakat BAZNAS

\begin{tabular}{|c|l|l|l|}
\hline No & \multicolumn{1}{|c|}{ Sektor } & \multicolumn{1}{c|}{ Jumlah } & \multicolumn{1}{c|}{$\%$} \\
\hline 1 & Ekonomi & 882.515 .274 .729 & 20,33 \\
\hline 2 & Pendidikan & 941.865 .099 .137 & 21,69 \\
\hline 3 & Dakwah islam & 979.468 .717 .694 & 22,56 \\
\hline 4 & $\begin{array}{l}\text { Kesehatan } \\
\text { masyarakat }\end{array}$ & 413.507 .938 .849 & 9,52 \\
\hline 5 & Sosial & 1.124 .150 .826 .782 & 25,89 \\
\hline \multicolumn{2}{|c|}{ Jumlah } & 4.341 .507 .857 .190 & 100 \\
\hline
\end{tabular}

Sumber : BAZNAS (2018)

Dari fenomena di atas dapat dilihat bahwa pola Penghimpunan masih dilakukan dalam bentuk metode penghimpunan tidak langsung dan merupakan satu metode yang mengunakan teknik atau cara yang tidak melibatkan partisipasi muzakki secara langsung (Rozalinda, 2015). Jika hal tersebut memungkinkan atau diperbolehkan. Manajemen Penghimpunan akan mampu mendorong tingkat pengelolahan dana zakat dengan baik. Agar program dan operasional BAZNAS Daerah Kabupaten Tapanuli Selatan terus berjalan maka mutlak dilakukan penghimpunan secara cepat dan strategis (Siregar, 2016). Penerapan metode penghimpunan tidak hanya dilakukan oleh LAZ dan BAZ akan tetapi juga dilakukan oleh perusahaan dan lembaga lainnya. LAZ sendiri ada yang skala nasional berjumlah 9 dan ada juga yang skala propinsi berjumlah 7 (Ramadhani, 2018). Data tersebut agak berbeda dengan yang diinformasikan oleh web resmi BAZNAS, yakni total ada 27 LAZ yang resmi terdaftar saat ini sesuai Peraturan Perundang-Undangan Pengelolaan Zakat (LAZ Nasional - PPID $B A Z N A S$, n.d.).

JISFIM: Journal of Islamic Social Finance Management, Volume 1, No 1 Tahun 2020 http://jurnal.iain-padangsidimpuan.ac.id/index.php/JISFIM 
Keberhasilan badan amil zakat tidak terlepas dari keseriusan dalam menjalakan aktivitas Penghimpunan maka eksistensi badan amil zakat akan berlangsung lebih lama. Beberapa penelitian terdahulu yang meneliti tentang stategi penghimpunan dana zakat pada Baitul Maal Hidayatulla (BMH) Surabaya yang mana temuan penelitiannya menyimpulkan bahwa faktor pendukung penghimpunan dana zakat Baitul Maal Hidayatullah (BMH) Surabaya yang pertama donatur tetap yang merupakan salah satu faktor pendukung dalam penghimpunan dana zakat, sehingga Baitul Maal Hidayatullah (BMH) Surabaya sudah mempunyai donasi dana tetap dalam penghimpunan dana. Kedua potensi zakat yang bisa dihimpun dan dikembangkan karena letak geografis, kepadatan penduduk dan pendapatan serta penghasilan penduduknya yang di atas rata-rata. Selajutnya penghambatnya ialah tingkat kesadaran masyarakat, pengetahuan masyarakat pada petugas penghimpun dana zakat dan tidak semua donatur memiliki handphone sehingga mereka seringkali ketinggalan informasi akan perkembangan Baitul Maal Hidayatullah (BMH) Surabaya (Buhari, 2018). Maka faktor keberhasilan dalam menghimpun dana zakat erat hubungannya dengan kemampua petugas dalam menghimpun dana zakat. Bertitik tolak pada latar belakang masalah di atas, maka tujuan dalam penelitian yaitu untuk mengetahui metode penghimpunan dan distribusi dana zakat pada BAZNAS Daerah Tapanuli Selatan saat ini.

\section{KAJIAN TEORITIS}

Zakat dari istilah fikih berarti sejumlah harta tertentu yang yang diwajibkan Allah untuk diserahkan kepada orang-orang yang berhak. Legitimasi zakat sebagai kewajiban terdapat beberapa ayat dalam al-Qur'an. Kata zakat dalam bentuk ma'rifah disebut 30 kali di dalam al- Qur'an, 27 kali diantaranya disebutkan dalam satu ayat bersama shalat, dan sisanya disebutkan dalam konteks yang sama dengan shalat meskipun tidak didalam satu ayat (Kompasiana.com, 2015). Di antara ayat tentang zakat yang cukup popular adalah surat alBaqarah ayat 110 yang berbunyi "Dan dirikan shalat dan tunaikkan zakat" (Quran Surat AlBaqarah Ayat 110 Arab, Latin, Terjemahan Arti Bahasa Indonesia, n.d.). Menurut Juwaini Penghimpunan diartikan sebagai kerangka konsep tentang suatu kegiatan dalam rangka penggalangan dana dan daya lainnya dari masyarakat yang akan digunakan untuk membiayai program dan kegiatan operasional lembaga sehingga mencapai tujuan (Huda, 2012).

Dalam melaksanakan penghimpunan, banyak metode dan teknik yang banyak dilakukan. Pada dasarnya ada dua jenis yang bisa digunakan, yaitu: metode langgsung (direct) dan tidak langsung (indirect). Metode langsung adalah metode yang menggunakan teknikteknik atau cara-cara yang melibatkan partisipasi muzakki secara langsung yakni bentukbentuk penghimpunan di mana proses interaksi dan daya akomodasi terhadap respon muzakki dapat seketika langsung dilakukan (Rozalinda, 2015). Beberapa hasil penelitian terdahulu juga menjelaskan bahwa ada dua metode penghimpunan dana zakat yakni direct JISFIM: Journal of Islamic Social Finance Management, Volume 1, No 1 Tahun 2020 http://jurnal.iain-padangsidimpuan.ac.id/index.php/JISFIM 
fundraising dan indirect fundraising (Setiawan, 2019). Salah satu strategi direct fundraising lainnya adalah dengan memanfaatkan teknologi informasi melalui Laku Pandai dengan perbankan syariah (Andiani, 2018). Saat ini memang syariah financial technology telah menjadi bagian yang penting dalam penghimpunan dana zakat (Zahroh, 2019). Namun demikian di beberapa wilayah di daerah yang masih memerlukan pemahaman terkait zakat masih efektif jika metode yang dipilih adalah secara langsung yaitu turun ke masyarakat (Mulyadi, 2018). Oleh karena itu kemampuan petugas zakat dalam menghimpun dana zakat secara langsung sangat penting (Almasuddini, 2019). Hal tersebut sebagai wujud pelayanan institusi yang menjadi faktor penting yang memengaruhi minat masyarakat menunaikan zakat (Djayusman et al., 2017). Sementara itu secara nasional, BAZNAS dalam Indonesia Outlook 2020 telah melakukan digitalisasi, disebutkan bahwa penghimpunan dana zakat di Indonesia adalah baik internal maupun eksternal sudah memanfaatkan teknologi informasi dan internet. Internal yaitu melalui: website, aplikasi sedangkan eksternal melalui ecommerce, raid-hailing, crowdfunding dan e-wallet (Outlook Zakat Indonesia_202o.Pdf, n.d.).

Distribusi dana zakat sebaiknya melalui zakat produktif (Hanifah et al., 2017; Nuzula, 2019; Riza, 2019). Namun demikian ada juga yang pendistribusiannya adalah ke arah konsumtif bukan produktif (Harisah \& Zainulloh, 2019). Sementara itu BAZNAS sudah melakukan digitalisasi dalam distribusi zakat yaitu melalui rice ATM dan Sistem Database berbasis Zakat (Outlook_Zakat Indonesia_202o.Pdf, n.d.). Hal tersebut tentu berbeda dengan yang berada di daerah-daerah yang belum tersentuh teknologi informasi dan internet. Dimana pendistribusian dana zakat BAZNAS yang bersifat produktif dalam beberapa bidang yaitu: ekonomi, pendidikan dan kesehatan sedangkan yang bersifat darurat yakni: pendidikan, kesehatan, kemanusiaan dan dakwah-advokasi (Studies, n.d.).

\section{METODE PENELITIAN}

Penelitian dilakukan pada BAZNAS Daerah Kabupaten Tapanuli Selatan maka pengambilan datanya dalam bentuk primer, dengan jenis penelitian kualitatif adalah penelitian yang dilakukan di lapangan untuk memperoleh data dari informan secara langsung dengan mendatangi responden yang ada di lapangan (Ruslan, 2004). Sumber data yang digunakan dalam penelitian ini adalah data primer dan sumber data sekunder. Informan pada penelitian ini adalah ketua dan anggota BAZNAS daerah Kabupaten Tapanuli Selatan yang berjumlah 2 orang. Sementara itu, data sekunder diperoleh dari buku, publikasi, jurnal ilmiah dan data pendukung lainnya dari sumber resmi di internet. Untuk memperoleh data atau informasi, peneliti menggunakan teknik penentuan informan penelitian yaitu pemilihan informan yang dilakukan dengan sengaja dan ditentukan sesuai dengan informasi yang didapat (Bungin, 2007). Pengambilan informan juga didasarkan atas ciri-ciri, sifat-sifat atau

JISFIM: Journal of Islamic Social Finance Management, Volume 1, No 1 Tahun 2020 http://jurnal.iain-padangsidimpuan.ac.id/index.php/JISFIM 
karakteristik tertentu yang merupakan ciri-ciri informan; subjek yang diambil sebagai informan benar-benar merupakan subjek yang paling banyak mengandung ciri-ciri yang terdapat pada subjek penelitian; Penentuan karateristik informan dilakukan dengan cermat di dalam studi pendahuluan (Arikunto, 2006).

\section{Instrumen Pengumpulan Data}

Teknik pengumpulan data adalah cara mengumpulkan data yang di butuhkan dari lapangan dengan menggunakan instrumen-instrumen yang diperlukan dalam penelitian. Di samping menggunakan instrumen dapat pula dilakukan dengan mempelajari dokumentasidokumentasi atau catatan-catatan yang menunjang penelitian. Sebelum melakukan pengumpulan data maka hal yang terpenting adalah melakukan observasi (pengamatan langsung) kelapangan supaya tidak terkendala pada saat pelaksanaan yaitu: Wawancara; Observasi; Dokumentasi (Mardalis, n.d.).

Analisis data adalah mengelompokkan pada suatu urusan, serta menyingkatkan data sehingga mudah untuk dibaca. Urutan pertama membagi data atas kelompok atau kategorikategori, seperti sesuai dengan masalah dan tujuan, harus lengkap, dan dapat dipisahkan sehingga dapat memecahkan masalah (Nasir, 2005), Adapun teknik-teknik atau langkahlangkah yang dilakukan dalam analisis data kualitatif deskriptif adalah sebagai berikut: Editing data; Klasifikasi data; Menelaah seluruh data yang tersedia dari berbagai sumber; Reduksi data; Deskripsi data; Interpretasi data. Dimana untuk menjamin keabsahan data dalam penelitian ini, penulis berpedoman kepada pendapat Lexy J Moleong, yang dilaksanakan dalam beberapa tahapan yaitu: Perpanjangan Keikutsertaan; Ketekunan Pengamatan; Triagulasi.

\section{HASIL DAN PEMBAHASAN}

\section{Metode Penghimpunan Dana Zakat pada BAZNAS Daerah Tapanuli Selatan}

BAZNAS merupakan lembaga pemerintah non-struktural yang mandiri bertanggung jawab kepada Presiden, dan dibentuk dengan Keputusan (Keppres) RI No. 8 Tahun 2001 tanggal 17 Januari 2001. Dengan adanya keputusan Presiden, BAZNAS mendapat amanah dan berwenang melaksanakan tugas pengelolaan zakat secara nasional dengan melaksanakan fungsi perencanaan, pegendalian, pelaporan dan pertanggung jawaban atas pengumpulan, pendistribusian dan pendayagunaan zakat. BAZNAS Daerah Kabupaten Tapanuli Selatan menghimpun Dana (Fundraising) zakat, karena merupakah amanah Undang-Undang No 23 Tahun 2011 objek atau sasaran kerja BAZNAS Daerah Kabupaten Tapanuli Selatan terdiri dari 45 Aparatur Sipil Negara baik dari perorangan maupun Instansi Divisi penghimpunan zakat menerapkan metode penghimpunan dalam rangka menghimpun dana zakat pada tahun 2017 sampai dengan 2019 dapat dilihat pada Tabel 3.

\section{Tabel 3}

JISFIM: Journal of Islamic Social Finance Management, Volume 1, No 1 Tahun 2020 http://jurnal.iain-padangsidimpuan.ac.id/index.php/JISFIM 


\section{Data Penghimpunn BAZNAS dari Bulan Januari 2017-2019 Kabupaten Tapanuli Selatan}

\begin{tabular}{|c|c|c|}
\hline No & Tahun & Total \\
\hline 1 & 2017 & $543 . .465 .832$ \\
\hline 2 & 2018 & 521.704 .917 \\
\hline 3 & 2019 & 404.411 .936 \\
\hline
\end{tabular}

Sumber: BAZNAS Daerah Kabupaten Tapanuli Selatan (2019)

Dari Tabel di atas dapat terlihat dana zakat yang terkumpul cenderung menurun dari tahun ke tahun. Padahal divisi penghimpunan zakat dalam rangka menghimpun dana zakat menerapkan dua metode berbeda yang meliputi Direct Fundraising melalui telefundraising dan metode Indirect fundraising melalui penyelenggaraan suatu kegiatan melalui perantara dan menjali relasi. Hasil penelitian ini sejalan dengan penelitian yang dilakukan oleh Saparuddin Siregar yang berjudul "Problematika fundraising zakat: Studi kasus Baznas di Sumatera Utara" yang hasil penelitiannya menyatakan bahwa BAZNAS se-Sumatera utara tidak memiliki sumber daya manusia yang profesional. Ini disebabkan belum melakukan penyesuain dengan PP No 14 tahun 2014 dan juga tidak memadai anggaran yang tersedia dari pemerintah daerah/kota. Sumber daya manusia yang kurang professional, karena pada umumnya jabatan pengurus dijabat rangkap dengan tugas-tugas dari pemerintah, sehingga kelemahan profesionalisme SDM ini berimplikasi pada rendahnya perolehan dana zakat yang terkumpul disebabkan metode fundraising tidak dilakukan secara optimal.

Sementara itu, metode dalam penghimpunan dana zakat yang dilakukan BAZNAS Daerah Tapanuli Selatan meliputi:

\section{Direct Fundraising}

Metode direct fundraising yang di lakukan oleh BAZNAS Daerah Tapanuli Selatan ialah berupa kerjasama dengan ASN (Aparatur Sipil Negara), melalui UPZ (Unit Pengumpul Zakat) yang ada di kecamatan yang berkerjasama dengan BAZNAS Daerah Kabupaten Tapanuli Selatan, sehingga BAZNAS Daerah Kabupaten Tapanuli Selatan hanya menunggu kedatangan ASN untuk memberikan zakatnya baik melalui nomor rekening yang sudah diberikan maupun bagi mereka yang ingin langsung datang memberikan zakat kepada amil zakat pada BAZNAS Daerah Kabupaten Tapanuli Selatan serta beberapa donatur/muzakki yang sudah sadar akan kewajiban mengeluarkan zakat mereka. Kesadaran juga memengaruhi proses penghimpunan dana zakat (Buhari, 2018). Pada beberapa lembaga penghimpun dana zakat di Indonesia juga memperluas cakupan dengan menambah kantor cabangnya sehingga dapat secara langsung dalam proses penghimpunan dana zakatnya (Azis \& Sukma, 2016). Selain itu, pembagian unit kerja dan evaluasi penghimpunan dana zakat juga dilakukan pada penghimpun dana zakat lain di Indonesia (Almasuddini, 2019). Karena penghimpunan dana zakat secara langsung juga dipengaruhi banyak faktor diantaranya adalah keyakinan seseorang, layanan dari 
penghimpun dana zakat, pengetahuan agama seseorang dan pemujaan (Alisa, 2016; Badriyah \& Dita, 2020; Djayusman et al., 2017; Firdaus, 2018; Ivalaili, 2019; Larasati, 2018; Maulida, 2016).

\section{Indirect Fundraising}

Metode ini digunakan dengan menggunakan teknik atau cara yang tidak melihatkan partisipasi donatur secara langsung yaitu bentuk fundraising dimana tidak melakukan dengan melibatkan daya akomodasi langsung terhadap BAZNAS Daerah Kabupaten Tapanuli Selatan ialah menggunakan media dakwah yang mana pada saat penyaluran dana zakat maka pihak BAZNAS memberikan ceramah dan khutbah saat selesai magrib atau sebelum penyaluran zakat pada saat Safari muharram, safari rabiul awal, safari ramadhan, safarii maulid. Hal ini berlaku sama dalam metode penghimpunan dana zakat apapun, dimana kemauan seseorang/muzakki dalam membayar zakat dipengaruhi banyak faktor.

Sesuai dengan Undang-undang No.23 Tahun 2011 tentang pengelolaan zakat, BAZNAS Daerah Kabupaten Tapanuli Selatan juga melakukan metode pendistribusian dengan membagi kepada empat bidang yaitu, bidang ekonomi, pendidikan, kesehatan dan sosial berikut ini Tabel 4.2 mengenai distribusi zakat.

Tabel 4

Data Distribusi BAZNAS dari Bulan Januari 2017-2019 Kabupaten Tapanuli Selatan

\begin{tabular}{|c|c|c|c|c|c|c|}
\hline No & Tahun & Ekonomi & Pendidikan & Kesehatan & Sosial & Total \\
\hline 1 & 2017 & 350.000 .000 & 6.000 .000 & - & 34.400 .000 & 390.400 .000 \\
\hline 2 & 2018 & 330.000 .000 & 18.000 .000 & 8.000 .000 & 1.500 .000 & 357.500 .000 \\
\hline 3 & 2019 & 263.000 .000 & 13.000 .000 & 2.500 .000 & 25.900 .000 & 304.400 .000 \\
\hline
\end{tabular}

Sumber: BAZNAS Daerah Kabupaten Tapanuli Selatan (2019)

Perencanaan pendistribusian dana zakat pada BAZNAS Daerah Kabupaten Tapanuli Selatan berjalan dengan baik karena sesuai dengan alur dan program yang direncana BAZNAS Daerah Kabupaten Tapanuli Selatan. Salah satu fungsi zakat adalah fungsi sosial, yaitu sarana bersosialisasi antara orang kaya dan orang miskin. Kesenjangan ekonomi masyarakat menjadi permasalahan di Indonesia (Andiani, 2018). Agar dana zakat yang disalurkan dapat berdaya guna dan berhasil guna, maka dalam pemanfaatannya harus selektif, sehingga penyalurannya dapat terrealisasikan hasil penelitian pada BAZNAS Daerah Kabupaten Tapanuli Selatan mendistribusikan zakat pada empat Bidang yaitu bidang Ekonomi, Pendidikan, Kesehatan, Sosial. Sebagai pembeda, pada BAZNAS pusat Jakarta, pendistribusian dilakukan juga pada bidang dakwah (Indonesia Zakat Outlook 2019.Pdf, n.d.). Dana zakat pada BAZNAS daerah Kabupaten Tapanuli Selatan tidak didistribusikan pada bidang dakwah atau Islamic Preching. Padahal jika dilihat dari nominalnya, di BAZNAS pusat pada tahun 2017, telah 
mendistribusikan dana zakat sebesar 22,56 \%, nomor dua tertinggi setelah bidang sosial (social humanity).

Berdasarkan distribusi dana zakat pada Tabel 4.2, pada tahun 2017-2019 dapat dilihat bahwa distribusi dana zakat terbanyak adalah pada bidang ekonomi. Sementara itu, pada bidang lainnya nominalnya memang sangat berbeda jauh. Pada tahun 2019, distribusi dana zakat untuk ekonomi di Kabupaten Tapanuli Selatan adalah sebesar 86,39\% dari total dana zakat yang terkumpul di tahun tersebut. Sedangkan pada tahun 2018 adalah 92,30\% dan pada tahun 2017, sebesar 89,65\%. Meskipun memang, pengelolaan dana zakat pada BAZNAS daerah diserahkan sepenuhnya pada BAZNAS daerah Kabupaten Tapanuli Selatan. Maka memang pengelolaannya sangat tergantung kebijakan BAZNAS daerah yang seharusnya mempertimbangkan kondisi ekonomi dan kondisi lainnya pada masyarakat di daerah Kabupaten Tapanuli Selatan.

Keberhasilan dalam mendistribusikan dana zakat juga dipengaruhi oleh lembaga/institusi penghimpun dana zakat tersebut. Semakin jelas dan terbuka lembaga/institusi tersebut dalam mendistribusikan dana zakat maka kepercayaan masyarakat juga akan tumbuh semakin kuat. Hal ini menjadi bentuk penilaian masyarakat atau dalam hal ini muzakki pada kredibilitas, akuntabilitas dan citra positif lembaga/institusi penghimpun dana zakat yang ada termasuk di daerah seperti BAZNAS daerah Kabupaten Tapanuli Selatan. Jika kepercayaan meningkat maka keinginan masyarakat membayar zakat pada BAZNAS daerah Kabupaten Tapanuli Selatan juga meningkat. Dengan demikian, akan berpengaruh pada jumlah dana zakat yang terhimpun, dapat semakin optimal.

Hasil penelitian ini sejalan dengan hasil penelitian yang dilakukan oleh M.Musyfiq Hidayat yang berjudul "Evaluasi Penghimpunan dan Penyaluran Dana Zakat Pada BAZNAS Pusat” yang bentuk penyalurannya diantaranya pada bidang ekonomi,, bidang pendidikan dan dakwah serta bidang kesehatan dan sosial kemanusian. Serta evaluasi penyaluran BAZNAS Pusat melalui rekapitulasi jumlah dana zakat yang keluar dan realisasi penyaluran dana zakat.

\section{KESIMPULAN}

Berdasarkan hasil penelitian dan pembahasan pada bab sebelumnya dapat disimpulkan metode penghimpunan dana zakat menerapkan metode penghimpunan berupa kerjasama dengan ASN (Aparatur Sipil Negara), meliputi metode Direct Fundraising melalui telefundraising dan metode Indirect fundraising melalui penyelenggaraan suatu kegiatan melalui perantara dan menjali relasi pada BAZNAS Daerah Kabupaten Tapanuli Selatan, dan beberapa donatur yang memberikan zakat kepada Amil hanya bagi mereka yang sadar akan kewajiban menunaikan zakat. Sementara itu, metode distribusi dana zakat yang dilakukan oleh BAZNAS Daerah Kabupaten Tapanuli Selatan dengan metode langsung dengan empat 
bidang yaitu: Bidang Ekonomi (263.000.000) Pendidikan (13.000.00o) Kesehatan (2.500.000) dan Sosial (25.900.000). Saran yang dapat diberikan kepada BAZNAS daerah Kabupaten Tapanuli Selatan adalah melakukan evaluasi pada kedua metode penghimpunan dana zakat (direct dan indirect fundraising) sehingga proses penghimpunan dana menjadi lebih optimal dari yang sebelumnya, karena terdapat penurunan jumlah dana zakat yang terhimpuan. Selain itu, melakukan cara lainnya dalam sosialisasi pembayaran zakat dengan memanfaatkan media sosial, pesantren maupun lembaga pendidikan tinggi keislaman yang ada di Kabupaten Tapanuli Selatan. Sementara itu, dalam hal pendistribusian dana zakat, agar dapat mempertimbangkan pada bidang dakwah seperti yang sudah dilakukan pada BAZNAS pusat dan melakukan evaluasi pada proses pendistribusian dana zakat sehingga dapat menjadi acuan dan pertimbangan dalam pembagian persentase tiap bidang yang ada.

\section{DAFTAR PUSTAKA}

Abdulloh Mubarok dkk "Penghimpunan Dana Zakat Nasional ( Potensi, Realisasi dan Peran Penting Organisasi Pengegola Zakat” Dalam jurnal permana, Volume V, No 2 Februari 2014.

Abdurachman Qadir, Zakat dalam Dimensi Mahda dan Sosial. Cet. 2, Jakarta: PT. Raja Grafindo Persada, 2001.

Andri Soemitra, Bank dan Lembaga Keuangan Syariah, Jakarta: Kencana Kharisma Putra Utama, 2009.

Atik abidah, Analisis Strategi Fundraising Terhadap Peningkatan Pengelolaan Zis dan Lembaga Amil Zakat Kab. Ponorogo, Kodivikasi Vol.1o No 1 Tahun 2016.

Burhan Bungin, Analisis Data Penelitian Kualitatif, Jakarta: PT. Raja Grafindo Persada, 2007.

Dapartemen Agama RI, Al-Qur'an dan terjemahannya, Bandung: CV. Penerbit Diponegoro, 2011.

Dapartemen Agama, Manajemen Pengelolaan Zakat, Jakarta: Direktorat Pengembangan Zakat dan Wakaf, 2015.

Departemen Agama Republik Indonesia , Al-Qur'an Terjemahnya, Bandung: CV Penerbit JArt.

Depertemen Pendidikan Nasional, Kamus Besar Bahasa Idonesia, Jakarta: Balai Pustaka, 2001.

Didin Hafidhuddin, Zakat dalam Perekonomian Modern, Jakarta: Gema Insani,2012. , Zakat dalam Perekonomian Modern, Jakarta: Mutiara Dakwah, 2004.

Heri Sudarso, Bank dan Lembaga Keuangan Syariah, edisi 4, Yogyakarta: Penerbit EKONISIA, 2005), hlm. 265.

Huda Miftahul, Pengelolaan Wakaf dalam Persfektif Fundraising, Ponorogo: Kementrian Agama RI, 2012. 
Ilman. M. Akhyaruddin, Pengawai Badan Amil Zakat Kab. Tapanuli Selatan, Wawancara Pribadi, 29 Maret 2019.

Kartini, "Manajemen Baznas Kabupaten Musi Banyuasin dalam Jurnal Madina-Te, Volume 14 Nomor 2, Desember 2012.

Lexy J. Moleong, Metodologi Penelitian Kualitatif, Bandung: Rosda Karya, 2000.

M. Nur Rianto Al Arif Lembaga Keuangan Syariah, Bandung: CV Pustaka Setia, 2012.

Mardali, Metode Pendekatan Penelitian Suatu Pendekatan Proposal, Jakarta: PT BumiAksara, 2007.

Mardani, Fiqh Ekonomi Syariah, cet.1, Jakarta: Kencana Perdana Media Grup, 2012.

MohNasir, Metode Penelitian, Bogor Selatan: Ghalia Indonesia, 2005.

Monzer Kafh,dkk., Tanya Jawab Keuangan dan Bisnis Kontemporer dalam Tinjauan Syariah, Solo: PT. Aqwam Media Prifetika,2010.

Nasir Muhammad, Metode Penelitian, Jakarta: Ghalia Indonesia, 1998.

Rosadi Ruslan, Metode Penelitian Public Relation dan Komunikasi, Jakarta: Raja Grfindo Persada, 2004.

Rozalinda, Manajeman Wakaf Produktif, Jakarta: PT Rajagrafindo Persada, 2015.

Shihab M Quraish, Tafsir Al-Misbah pesan, kesan, dan keserasian al-qur'an, Jakarta: Lentera Hati 2002

Saparuddin, “ Problematika Fundraising Zakat: Studi Kasus Baznas di Sumatera Utara “, Miqot Vol.Xl No. 2 Juli-Desember 2016

Soerjono Soekanto, Pengantar Penelitian Hukum, Jakarta: UI Perss, 2010.

Sugiyono, Metode Penelitian Kuantitatif, Kualitatif dan R\&B, Bandung: Alfabeta, 2008.

Suharsimin Arikunto, Prosedur Penelitian Suatu Pendekatan Praktik, Jakarta: Rineka Cipta, 2006.

Sulaiman Rasjid, Fiqh Islam, Bandung: Sinar Baru Algensindo, 2004.

Sutrisno Hadi, Metodologi Research, Yogyakarta: AndiOffit, 1991.

Umrotul Khasanah, Manajemen Zakat Modern, Malang: UIN Maliki Press, 2010.

Uswatun Hasanah, "Pengaruh Kualitas Sistem Dana Proses Jasa Lembaga Zakat Berdasarkan Model Carter Terhadap Tingkat Kepuasan Muzakki (Studi Kasus LAZIS UII Yogyakarta)" Tesis, tidak diterbitkan, Program Pascasarjana Universitas Islam Indonesia, Yogyakarta, 2008

Wahbah Al-Zuhayly, Zakat Kajian Berbagai Mazhab, Bandung : PT. Remaja Rosdakarya, 2000.

www.baznas.go.id

Yusuf Qardawi, Musykilah Al-Faqr Wa Kaifa Alajaha Al-Islam, Beirut: Muassasah AlRisalah, 1985. 